\title{
The Impact of School Leadership on Parental Engagement: A Study of Inclusion and Cohesion
}

\author{
Agata Mleczko \\ School of Education, University of Nottingham \\ Jubilee Campus, Wollaton Road, Nottingham, NG8 1BB, United Kingdom
}

Alison Kington (Corresponding author)

Institute of Education, University of Worcester

St. John's Campus, Henwick Grove, Worcester, WR2 6AJ, United Kingdom

Tel: 44(0)1905 542025 E-mail: a.kington@worc.ac.uk

\begin{abstract}
Received: June 1, 2013 Accepted: July 22, 2013 Published: August 16, 2013
doi:10.5296/ire.v1i1.3844 URL: http://dx.doi.org/10.5296/ire.v1i1.3844
\end{abstract}

\begin{abstract}
This article focuses on the role played by principals in enhancing parental involvement in primary schools. The schools involved in this research were characterised by a high presence of ethnic minority children and were located in a neighbourhood of low social and economic status in the Midlands region of the United Kingdom. Qualitative methods were employed in order to explore the influence of strong leadership on engagement of the parents. The study spanned a period of four years, giving an opportunity to examine sustainability of the activities introduced by the principals and staff. The findings reported are based on data collected from an Infant and Junior School involved in a number of extra-curricular and curriculum-enhancing projects. It argues that strong leadership fosters engagement of parents in school activities and thus academic achievement of pupils improved over time. The findings bring evidence that the role of the school principal is crucial in the introduction, implementation and sustainability of solutions focused on parental involvement, as well as bringing benefits to the social cohesion of the local community.
\end{abstract}

Keywords: Parental involvement, leadership, inclusion, social cohesion, community. 


\section{Introduction}

A strong relationship between schools and parents has long been considered beneficial to pupils, and especially important for improved social cohesion in schools and the wider community (e.g. Rosenberg \& Lopez, 2011; Rosenberg, 2012). In addition, over the past twenty years, many studies in the United States and in Europe have explored this issue from different perspectives, addressing (amongst other issues) security (Adelman \& Taylor, 2008), school outcomes (Hoover-Dempsey \& Sandler, 1997; Thurston, 2005), chronic absenteeism (Sheldon \& Epstein, 2004), homework (Harris, Andrew-Power, \& Goodall, 2009), and poverty (Ciuffatelli Parker, Grenville \& Flessa, 2011). A variety of initiatives targeted at encouraging a close partnership between school, parents and the community have been observed which have included expanding afterschool academic programs, providing systems of 'wrap-around' care, conflict mediation and violence reduction, encouraging mentoring, and one-to-one support.

Thorough exploration of the benefits related to the engagement of the parents in formal education has shown that "students whose families are engaged (...) are more likely to:

(1) earn higher grades and test scores and enrol in higher-level programs;

(2) be promoted, pass their classes, and earn credits;

(3) attend school regularly;

(4) have better social skills, show improved behaviour, and adapt well to school;

(5) graduate and go on to post-secondary education (Henderson \& Mapp, 2002, 7).

Despite the strong evidence of benefits, the image of parental involvement in schools as a solution to all contemporary social challenges related to poverty, inequality, and high drop-out rates is not straightforward. More than ten years ago the new holistic role of schools was argued (Martin, Linfoot, \& Stephenson, 1999). However with the pressure of an increasingly diverse society and a growing number of high-risk communities on the one hand, and the necessity to mobilize the human and material resources needed for academic success on the other (Sanders \& Harvey, 2002), schools have been forced to look for new ways to successfully realize the new targets.

The role of schools in a contemporary society has been dramatically modified throughout the last twenty or so years. One of the manifestations of the mobilization of the human resources took the shape of parental participation in formal education. Due to a growing number of research studies arguing the benefits of parental involvement in schools (Auerbach, 2009; Epstein \& Salinas, 2004; Sheldon \& Epstein, 2004; Martin et al., 1999), changes to education policy were made across the world that encouraged and supported schools in the fostering of parental involvement.

This collaboration encouraged by the British government in the late 1990s was constrained by rigid boundaries which dictated, for example, the proportion of parents on school governing bodies, and their level of involvement parents should have in the decision making 
process. Although seen as a positive way of addressing social inclusion and cohesion issues, the partnerships developed in local communities have been blamed for resulting in an inequality between parents who are of more affluent backgrounds and those who are less skilled in exercising their rights. So although the role of parents had been transformed it has been described as more representative than participative. It was later confirmed in research by Park (2008), and Warren, Hong, Rubin and Uy (2009) that this strategy of encouragement and support to become involved in school activity was somewhat restricted by the socio-economic status of the parents which, in turn, had a direct impact on the social capital they possessed. The participation of parents as supporters of the educational careers of their children was widely accepted as a solution to societal challenges. However, the strategies for the involvement and sustainability of this policy were less clear.

It is argued by many that the key facilitator of increased parental engagement is the school principal and their leadership, and that it is through this role that successful solutions will be found (e.g. Bouffard \& Stephen, 2007; Griffith, 2001; Ho, 2009). The next section examines the two main conceptual contributions to this debate, exploring the ways in which school leadership can act as the pivotal force in any change in social cohesion.

The findings reported here were collected as part of a 4-year study commissioned by the European Union. The UK was one of fourteen European counties that participated in the project and the key aim of the research was to identify educational interventions that were being facilitated by school leaders and conducted within learning environments that were aimed at improving parental engagement and, in turn, the learning experience of pupils. Specific research questions related to this overall aim, and which will be addressed in this paper, were as follows:

i) How do principals facilitate increased parental engagement in primary schools?

ii) What are the ways in which opportunities for parental participation and engagement can be increased in the learning environment?

iii) How can cultural diversity be celebrated within learning situations?

Before presenting the findings in each of these areas, the key literature relating to leadership and parental engagement will be discussed.

\section{Conceptualizing Theories}

\subsection{Leadership in Schools}

The critical role of school leadership in enhancing cooperation with parents is attributed to the positive activity of principals, and the nature of this overall process has been conceptualized in two basic ways. The first strand is related to the leadership described as 'instructional leadership' (Bredeson, 1985) which requires a set of particular skills starting with: good understanding of the instructional programs so he/she is able to actively guide teachers in its implementation; through good judgement of the quality of teaching in order to select and maintain good teaching staff; and special capabilities for leadership-recruiting loyalty to the common task of teaching a specific group of children (for details see: Fink and 
Resnick, 2001, 5-6). While instructional leadership emphasizes the agency of the principal described as the "intellectual glue" of the system (Fink \& Resnick, 2001, 8), the second strand puts even greater responsibility on the school leader.

Fullan argues that the principal of the future should be a "leader in a culture of change" $(2002,1)$. He explicitly states that "the principal as instructional leader has been a valuable, but too narrow a solution" (Fullan, 2002, 1). In order to increase, not only the success of schools in terms of high levels of pupil achievement, but also sustainability of solutions, the principal "has to be much more attuned to the big picture, and much more sophisticated at conceptual thinking, and transforming the organization through people and teams" (Fullan, 2002, 3). To this end, principals' behaviour was explored by Griffith (2000) in order to describe the particular leadership styles and their influence on fostering parental involvement and pupil achievement. He concluded that, regardless of the type of leadership (master teacher, administrative agent, gamesman/politician, school manager, maintenance manager or missionary), none could be guaranteed as successful, regardless of context. For example, in some aspects of school-parent relationship (e.g. attendance of Parent Teacher Association meetings), there was more success when the principal behaved like "school manager", whilst other styles had little or no effect in that context. The most successful principals were seen to simply recognize that "improvement is more a function of learning to do the right thing in the setting where you work" (Fullan, 2002, 11).

The common ground between both concepts is related to the belief that the success of the school as an institution goes beyond the principal alone. It is believed that "it is impossible for principals to meet all of the instructional needs of a school" therefore it is necessary to distribute the leadership "across people, routines, and tools" (Sherer, 2008, 2). The distribution of leadership requires a high level of involvement from staff and the parents, thus principals attempt to build a communication structure of direct encouragement (Sherer, 2008). Research reporting the views of parents on leadership and strategies for their involvement in school emphasizes three crucial points: (1) "the school community has to be seen to welcome parents into the school, (2) participation is seen as a valuable asset and resource, and (3) the school needs to connect with parents through a focus on the children and their learning" (Mapp, 2003, 55). The principal, teachers and other staff members need to communicate with parents in ways that "welcome them and demonstrate a sincere desire to include them in the life of the school" (Mapp, 2003, 56). Successful schools are also said to affirm parents' efforts to be involved in their children's education (Mapp, 2003), through encouragement and support by the principal (and others) to work on various decision-making committees and projects (ibid). Parents emphasized that "relationships with staff were reciprocal, with ideas and feedback shared in a way that gave parents' contributions equal weight and importance" (Mapp, 2003, 57). Lastly, parents felt connected to the school through a central placement of the children's education, which created an opportunity to focus on a goal that was meaningful and important to both parties (Mapp, 2003).

Views on leadership have evolved from concepts focused on leadership traits (Burns, 1987) and behaviours (Hallinger \& Hausman, 1993), through institutional theory (DiMaggio, 1988) towards distribution of leadership within the organization (Gronn, 2000; Spillane, Halverson, 
\& Diamond, 2004). As all individuals in schools have some degree of agency (Sherer, 2008), it is necessary to include staff and parents in any discussion on leadership. It is crucial for principals to share responsibilities, to allow teachers to take the lead in a variety of activities, and most of all to encourage teachers and other school staff to initiate and sustain relationships with parents. Despite the strong leadership influence, teachers need to have choices regarding their participation in distributed leadership and have opportunities to develop their ideas (Sherer, 2008).

Many academics (e.g. Warren et al., 2009) argue that schools need to build the capacity of parental involvement by focusing on the development of relevant skills and knowledge, as well as a sense of power and self-efficacy. Warren and colleagues provide strong evidence that, in disadvantaged communities, empowerment of parents through courses and workshops provided by the school is especially important (Warren et al., 2009). Strong participation in school activities not only improves the academic achievements of the pupils, but also allows parents to meet, cooperate, feel empowered and develop transferable skills.

\subsection{Parental Involvement in Schools}

Further to reconciling two approaches to school leadership, the literature also brings together two important strands relating to parental involvement strategies. The first strand argues that formal involvement is crucial and gives the opportunity to parents for sharing responsibilities and a sense of achievement (Barth, 1990). It argues that formal participation in school councils should be strongly encouraged. However, research also shows (Davies, 1988; Park, 2008) that formal encouragement targeted at parents is more effective in more affluent socio-economic groups, resulting in further inequality.

In order to deal with this challenge, the second strand of literature argues that informal relationships between the school and parents is more effective and successfully supports the involvement of those from less affluent socio-economic groups. Denessen, Bakker and Gierveld (2007) argue that when formal encouragement is disproportionally large it brings with it negative effects and frustration from the school staff and non-participating parents, whereas when schools hold a more informal attitude towards parents "it seems to be easier to stimulate minority parents' involvement" (Denessen et al., 2007, 30). However, when parental involvement in school is limited to the informal aspect it can be seen to result in a lack of communication and some parents feeling marginalised. Principals who combine both strategies - formal and informal involvement of parents - are more likely to be successful than those whose activities are too narrow.

In summary, this paper argues that the advantages parental involvement should be deeply embedded in the general vision of the school and that this should be led by the principal of the school. Furthermore, principals who distribute the school leadership amongst staff and parents are more successful (Harris, 2007). The discussion here will demonstrate that, with strong leadership, schools can successfully engage positively with parents to improve teaching and learning opportunities and social inclusion, and that this can be achieved in a way that is sustainable. 


\section{The Study}

The main aim of the research was to identify educational interventions that were being facilitated by school leaders and conducted within learning environments that were aimed at improving parental engagement and, in turn, the learning experience of pupils. The findings reported here are based on data collected from an Infant and Junior School involved in a number of extra-curricular and curriculum-enhancing projects involving teachers, pupils, parents and the wider community.

In order to select schools for participation in the project over a four-year period, a number of criteria, stipulated by the European consortium, were applied. Schools had to demonstrate, in advance of selection:

(1) a contribution to academic success (as defined by children's educational attainment) in relation to their specific social context. By this, it signified that students in the school selected obtained higher levels of educational attainment in comparison to students in schools located in similar socio-cultural and socio-economic contexts;

(2) a number of social characteristics, including low socio-economic status and students with a minority background; and

(3) a strong attempt to overcome inequalities through having strong links with community and a record of positive community involvement in the school.

It is important to note that the criteria associated with achievement was not meant as a benchmark by which to evaluate or assess the initiatives, but purely as a demonstration of a positive trajectory of children's learning. Furthermore, the selection criteria, adhered to by all participant countries, meant that, by definition, schools involved in the research were already able to demonstrate a positive approach to teaching and learning within challenging educational and social contexts. This, in turn, could also suggest a greater likelihood of positive responses to new initiatives and opportunities within the school by staff.

\subsection{The Schools}

Lakeside Avenue School [1] is divided into two separate school buildings: the Infant School (ages 4-7) which also houses a nursery school (taking children aged 3-4), and the Junior School (ages 7-11). They are both state maintained foundation schools and each school has its own head teacher. The number of students on roll in 2011 at the Infant/Nursery site was 284 and at the Junior site, the number on roll was 311. At both sites, there are an above average number of students who have learning difficulties and/or disabilities, but who are without a statement of Special Educational Needs (SEN). As a consequence, the schools have established close working relationships with the local government support services. Although located in two separate buildings, there is a tight, community-driven relationship between the Lakeside Avenue Schools and teachers, and administration work closely together. For the purposes of this paper, we examine both schools together as one cohesive school system. 


\subsection{Social and Economic Characteristics}

The Lakeside Avenue schools are very diverse, inner city schools in the Midlands region of the UK. The schools are located in the neighbourhood of 'Callaton' [see Note 1], with a population of just over 40,000 according to the 2001 census. Callaton is a socially and economically deprived neighbourhood, which has suffered for many years from long-term disadvantage. As a result of economic shifts away from manufacturing, the neighbourhood has experienced long-term unemployment and faced challenges of overcoming social disadvantage, poor housing, poverty, drug abuse, crime, health issues, learning difficulties and exclusion. According to the Office for National Statistics (2007), the deprivation indices for individual neighbourhoods, ranks Callaton as one of the most deprived areas of England. A total of $26 \%$ of pupils at Lakeside Avenue Junior School and 29\% of those at Lakeside Infant School were eligible for free school meals which is higher than the national average $(17 \%)$.

The community of Callaton is a socially and ethnically diverse neighbourhood, with a majority of British-born residents of Pakistani, Indian and African-Caribbean origin and the school intake reflects that with a higher proportion of students from minority ethnic backgrounds than the national average. In 2010-2011, the percentage of students of ethnic minority backgrounds at the Infant School was $88 \%$, and the percentage of Black and Minority Ethnic (BME) students at the Junior School was 82\%. At both schools, the largest represented minority ethnic group is made up of students of Asian heritage.

\subsection{Educational Achievement}

The Lakeside Avenue schools are successful; the Key Stage 1 and Key Stage 2 contextual value-added (CVA [2]) measure is 100.8, signifying that the school is performing better than similar schools across the UK. In the Infant School, data for Key Stage 1 shows that all pupils are performing significantly higher than expected and improving relative to schools nationally in English, mathematics and science. These data also show that minority ethnic students (particularly of Asian-Pakistani origin), students who are known to be eligible for free school meals, and students with Special Educational Needs (SEN) are all performing significantly higher than expected and improving, relative to schools nationally. For the Junior School, data show that children aged 7-11 are achieving scores in excess of the national average for English, maths and science.

\section{Methods and Sources of Data}

Data collection was oriented towards the understanding of how parental involvement in schools contributes to strengthen connections between education and diverse areas of society, and how this involvement is facilitated by school leadership. To address this issue, the project adopted a mixed methods approach that included both survey and case study strands. Data generation involved the collection (over four academic years) and preliminary analysis of principal, teacher, pupil and parental level data, as well as data collected from representatives from external organisations. This allowed the combination of context-specific factors over four rounds of fieldwork. The study sought to establish a multi-dimensional picture of social 
and community cohesion by integrating a range of perspectives, observations and included a contextual perspective based on level of disadvantage of school intake.

Having gained ethical approval, the school principals were provided with information on the ethical procedures of the project. Each participant in the study was provided with a written description of the project and, if they agreed to participate, was asked to sign a consent form.

This paper draws on the analysis of data generated via semi-structured, face-to-face interviews which were carried out with representatives from community organisations, local government and practitioners [3]. Qualitative methods were particularly useful in order to generate in-depth, descriptive and communicative accounts, allowing for a perspective of "the nuances of increasing complexity" of the elements of the case study (Stake, 1995, p. 21). The design of the case study followed a semi-structured format for interviews with members of staff, pupils and parents. Although there was an established pattern of questions for each interview to follow, the questions were largely open-ended and reflective. At the end of each interview, participants were also asked if they would like to share additional information and perspectives that they thought and found were relevant at any point during the interview. In this way, the interviews allowed for the participant to expand on multiple issues pertinent to the case study. For all interviews, participants were selected according to a maximum validation sampling strategy, which allowed for the widest variety of individuals to be represented in the project, by gender, ethnicity, and religion, and in the case of pupils, age and ability.

In addition to interviews, daily life stories were conducted which allowed the researcher and the participants to engage in a dialogue regarding their perceptions of parental engagement. All daily life stories were conducted at both schools, during school hours. Table 1 summarizes the types of data that were collected and the participant groups involved.

Table 1. Qualitative data sources

\begin{tabular}{ll}
\hline Qualitative Data & Spaces and Participants \\
\hline Interviews & Representatives of community organizations \\
& $\begin{array}{l}\text { Representatives of local government } \\
\text { Professionals in school staff }\end{array}$ \\
\hline \multirow{2}{*}{ Daily life stories } & Family members of students \\
& Students attending school \\
\hline Focus group & $\begin{array}{l}\text { 6-10 professionals: teachers, advisors, social educators and other } \\
\text { professionals }\end{array}$ \\
\hline Collected school \\
documents
\end{tabular}$\quad \begin{aligned} & \text { Mission statements, Ofsted reports, Headteacher reports to Governors, } \\
& \text { School improvement plan, school prospectus, new revised version of } \\
& \text { Home School Agreement }\end{aligned}$


The data generated through the above qualitative sources were first transcribed verbatim. To maintain anonymity and confidentiality of participants, all identifying characteristics were removed and names were removed and/or replaced by pseudonyms. The team developed a Code of Conduct, which adhered to ethical guidelines developed by the British Educational Research Association. This covered issues such as participation, consent, confidentiality, anonymity, and the right to withdraw from the study. Having gained ethical approval, the head teachers were provided with information on the ethical procedures of the project. Each participant in the study was provided with a written description of the project and, if they agreed to participate, was asked to sign a consent form. All interviews were audio-recorded.

\section{Findings}

\subsection{How Do Principals' Facilitate Increased Parental Engagement in Primary Schools?}

In discussing the findings of this study it is important to firstly consider the nature and characteristics of the principals themselves. Both of these individuals were considered strong leaders by staff members in their schools and by the local community. They had both been in post as school principals for a number of years and had previous experience of this role in other schools. Central to their identity as principals was a strong commitment to improving these schools, the learning experiences of the pupils, and the development of an holistic approach to social inclusion and cohesion.

I knew something had to be done or I wasn't sure what would happen to these children further down the line (Junior School Principal)

Facing a highly disadvantaged population and high level of ethnic and cultural diversity of pupils enrolled, it was clear that parental involvement was crucial to the schools' improvement.

It was clear that they had so much to give and that it was just a matter of getting them involved - of course, that came with problems because many of them had had bad experiences of school themselves or just didn't know how to behave in a school environment (Infant School Principal)

Both principals have worked together and began by focusing on a clear vision for the schools, looking for the best practices in similar settings. They were committed to a common vision across both settings and involving members of staff in this development.

It was vital that the staff were on board with it or else it wouldn't have worked.

Most were but there some that didn't like the changes and they are no longer here (Junior School Principal).

In support of their aims, the two principals favoured a two-way communication with staff to gather all ideas and to support the implementation of changes. Inclusion of the teachers' and parents' ideas was seen as a sign of distribution of the leadership, which gained favour from teachers.

We were really included and that made us want to buy into it. They were quite 
major changes so it would have been difficult for anyone who didn't support them. Most members of staff were optimistic of what was happening which I think was quite surprising in a way. I mean, we're always getting things thrown at us by the Government and have to react to things really quickly, but this was different. Involving parents and families should have made things harder but it didn't. It made things a lot more fun (Teacher).

The school leaders demonstrated openness and positive attitudes towards parents which started to result in higher involvement of parents across all ethnic and cultural backgrounds.

This rapid success, however, did not come easily. Both principals were faced with serious problems related to high absenteeism of pupils who persistently travelled overseas during the school year to visit relatives which often resulted in long periods of no schooling.

We did encounter problems and still do but now we have really positive relationships with parents and they know we value their involvement in a range of school activities so we have created an environment where we can have open and honest discussions about these things. Most things can be resolved (Junior School Principal).

I can talk to the school about things now because I feel far more confident going in there. I love helping out and it makes me feel really good that I have something to share with so many of the children (Parent).

Through clear communication with parents, and series of workshops focused on parental skills, they were successful in lowering the number of families that took holidays during term time, thereby increasing the level of attendance. Clearly communicated expectations and a focus on pupil achievement in conversations with parents resulted in positive responses to issues where there had previously been problems.

The skills of communication, diplomacy, and interaction alongside creative, forward-looking ideas were shown to be successful in terms of the development of relationships with parents and their subsequent increased involvement with school activities. However, key to this process were the initiatives taken forward by the principals in order to engage parents within the learning environment and celebrate the cultural diversity within the local community.

\subsection{What Are the Ways in Which Opportunities for Parental Participation and Engagement Can Be Increased in the Learning Environment?}

There follows a presentation of key findings which demonstrates the breadth of activities facilitated by the principals of these two schools and which were targeted at increasing parental engagement with the school in order to improve pupils' learning experiences.

\subsubsection{Family Literacy Sessions}

In the Infant/Nursery school, parents were encouraged to bring their child into the school and accompany them into their classroom. Once a week this was followed by a literacy sessions where parents or family members were invited to stay and read a book with their child or a 
group of children. This activity was extended on occasion to include participation in particular activities to coincide with cultural festivals or religious holidays:

...learning activities where you bring your mum to school or you bring your dad to school...as part of the raising aspirations and you know the spiritual, moral, social, cultural aspects of learning (Staff member).

Interview data collected from pupils indicated that the support of family and community members helped to improve their academic progress. All pupils interviewed stated that they would like their own parents to participate more in school because they felt it would help improve their learning. With the participation of family and community members in classrooms and learning activities, children were provided with greater one-to-one support, which helped their academic achievement. One parent stated:

Some children need a little bit more attention than others and it's nice for them to be able to go to somebody else other than the teacher...they seem to like people coming in helping" (Parent).

An example of this was evident in data collected from two community volunteers who worked one-to-one with several children throughout the course of a year. Their main remit in school was to work individually with particularly children who were facing challenges in their literacy work. Many are "not fluent readers" (Community volunteer). One of the volunteers stated that the purpose of her work as a volunteer was:

to build up relationships with children, just one child at a time... We can read to them because sometimes the children don't always have reading at home or the parents have got a different language, we get them to read as well, but we don't put any pressure on them, the idea is to make reading seem fun. So we play games as well. (Community volunteer)

The sessions were oriented towards reading a range of books, discussing vocabulary and playing games "to motivate them...it's very important to make sure the child is not bored" (Staff member). One of the central aims was to improve children's enjoyment of reading and literacy activities, and through that enjoyment, improve their literacy skills. This form of community participation was seen to have a positive impact on children's achievement. For example, one of the volunteers reflected,

...one girl that I have at the moment... when we started off...she could hardly read, and... [now with the same books] I found she could read it. So I do find there's a definite difference" (Community volunteer).

This pupil's interest in reading and self-confidence improved to the point of being motivated and enthusiastic about reading at the end of the school year. Through individual sessions, volunteers from the community raised awareness about reading in children and improved their overall self-esteem and self-confidence. Children also received one-to-one attention and received praise from teachers in the school. As one volunteer stated:

One of the things that helps, because the teachers are so positive about it, the 
children take things back [to] show them to the teacher [and] she praises [the children]...it's the actual partnership that is very important (Community volunteer).

The success of this particular initiative was evidenced by the partnership that developed between the parents, family members and the school. This partnership strengthened over the course of the project and beyond. Parents who had not known how to participate in their child's learning were able to do so in a way that was fun and educational.

\subsubsection{Creative Partnerships}

The schools also have on-going links with the Creative Partnership programme [4], a Government project based on the idea that to raise the academic achievement and motivation of young people, there needs to be support and assistance given to schools to partner with:

...creative professionals - from architects to scientists to multimedia developers and artists...to use creativity to solve problems and see real improvements in pupil behaviour and school performance (Creative Partnership).

There have been a number of improvements for children, parents, teachers, the school and the wider community as a result of activities included in the Creative Partnership programme. An example of one of these is the Gardening Club at the Infant/Nursery School. The idea for the Gardening Club originated from a community volunteer at the school who had heard of the work that Creative Partnerships did and what it could achieve if supported.

The Creative Partnership programme at Lakewood Avenue Infant/Nursery School has shown benefits for children at an early stage:

...in terms of communication, language, is fantastic and certain children who...find a certain kind of, an academic approach you know will come out of themselves and you'll see quite a different side to certain children... a lot of them are just passionate about doing it (Community volunteer).

The collaborating teacher stated:

it was interesting as a teacher, and as a Creative Partner, to see the children with their parents and how they interact and you know, you see another side to the child...things start to click...in terms of getting to know your child better...seeing their parents and understanding more about their background is really, really valuable. (Staff member).

The Gardening Club sessions were held once a week and have become an important tool in the school's aim of enhancing parental involvement in school activities and creating opportunities for parents and children to work together. As the organizer stated,

...the project isn't just about gardening really, it's very much about giving parents and children the opportunity to do something together, you know to have that quality time" (Community volunteer). 
The work of the Creative Partnerships programme is not unique to the Lakewood Avenue schools. However, the way in which the initiative was embraced and extended in order to facilitate parental engagement in children's learning was a strength of the school curriculum. The opportunity this programme offered for learning 'beyond the classroom' meant that parents who were not familiar or comfortable with traditional learning environments could participate for the first time, often as the 'expert' delivering the session, in alternative outdoor or creative lessons.

\subsubsection{Peers Early Education Partnership sessions (PEEPs)}

The Peers Early Education Partnerships sessions (PEEPs) were two hour sessions run twice a week for parents and their young children. Although situated in the hall of the Infant school, it was widely used by parents with children in both the Infant and Junior Schools. The session allowed them to remain in the school environment and use the soft play and apparatus with babies and pre-school children. For parents, the PEEP sessions have allowed for community-building and friendships to form:

We have parents that go out for dinner and meet up because they've met in PEEPS (Organisational rep).

The senior management team of the Infant and Junior Schools support this notion:

...schools these days aren't just about education, they are very much to do with social care. The in-school coordinator coordinates all the support for families that the school can access for them and that includes helping them to participate in social activities where possible (Staff member).

School staff noted that literacy skills were more developed among children who had participated in PEEP sessions. As one teacher stated: "the children who participate in the PEEP sessions had more developed language and literacy skills, and moreover, the transition into the nursery can be for the children and parents if they participated in PEEPS 'Stay and Play' (Community volunteer).

As with the family and community education courses, activities such as the PEEP sessions have an impact upon parent's perceptions of the school: "seeing the school as a place to be rather than just a place where their children go and learn" (Staff member). Parents reported that, through engaging with the school in a variety of ways, they gained a better understanding of the importance of education and a clearer understanding of how education can empower their child (Parent).

Parents who participated in learning activities at the school reported that they often gained a sense of enjoyment and fulfilment themselves, as well as a connection to the school community. Through attending school trips, reading with children during literacy sessions and attending swimming lessons, one mother stated that she "enjoyed it as much as the children" and felt connected to the community (Parent). 
5.3 How Can Cultural Diversity Be Celebrated within Learning Situations?

In another initiative to involve family members in the school, parents were invited to instruct and lead activities. At the Junior School,

parents of years 5 and 6 have been encouraged to come in and speak to the classes, so we've had, there were things like stick dancing, it's bringing in other cultures and people talking about countries, because obviously there's quite a high migrant population...they have encouraged those...more of an ad hoc basis...it normally ties in with something that they're learning at the time...it could be more geographical, it could be cultural, it could be music related. (School governor).

Given the diversity of the student population and the high percentage of students from minority ethnic backgrounds, the school incorporated religious and cultural festivities and celebrations into the curriculum throughout the year and invited parents and other family members from a number of religious communities to contribute to these. One participant stated, "every religious festival is at least acknowledged if not celebrated at the school" which leads to a greater understanding of the times of year when students might be more likely to be absent or an understanding of the needs of individual students who are fasting (Staff member). There was also a Christmas Fair that was organized and coordinated by parents, which often included strong family and community participation.

Participants discussed family and community participation in school as a way of furthering community cohesion. Lakewood Avenue schools were multicultural environments, which resulted in the positive participation of family and community members from different ethnic backgrounds in classrooms and learning spaces which, in turn, aided cohesion within the local community. For example, one parent stated that learning activities focused on the cultural, ethnic, religious or national backgrounds of families of children "brought everybody together" (Parent). A member of the school staff stated:

We have a really good mix of people...you could tell that there was a really good buzz, there was a really good feeling that people were all mixing together and joining in and appreciating other people's cultures...you did get a feeling that people were happy, enjoying each other's company and talking to one another which they wouldn't do in their own everyday lives, they probably wouldn't actually come into contact with each other, because they go to different places of worship, they probably go to different shops for their food. And if schools don't, can't have on offer multicultural events where people are being drawn together and mixing there aren't really that many other outlets where it's not completely forced you know, it's something because their kids go there. (Staff member).

In this way, the school becomes "a hub of the community" (Staff member). A variety of the initiatives undertaken by the school have resulted in improvements in academic achievements of the pupils and social cohesion. Through participation in education of their children parents and volunteers have been gathered around the school which started to play important role in a local community. School is considered a neutral place, bringing parents and their children, of 
all ethnic backgrounds, together.

\section{Discussion}

Findings from these case studies highlight the importance of the school principal in facilitating opportunities for increased parental engagement. The case study data show that, as part of establishing a culture in schools that encourages parental involvement, it is important that the leadership vision for the school is clearly communicated, and responsive to the school and community context. Furthermore, this vision needs to be positive and optimistic in tone if members of staff are to feel that they have the opportunity to innovate and be part of a team that can achieve the goal of continuing to foster improved parental involvement. Mapp (2003) reports that: "when school personnel initiate and engage in practices that welcome parents to the school, honour their contributions, and connect them to the school community through an emphasis on the children, these practices then cultivate and sustain respectful, caring, and meaningful relationships between parents and school staff' (Mapp, 2003, 36).

Although the project described above was successfully implemented and sustained, this is not the general tendency in UK schools. As mentioned in the introduction of this paper parental involvement in educational policy has been mainly focused on formal participation in school committees rather than actual support of the learning process and overall development of pupils. The leading role of principals described in this text is not always apparent. It is true, especially in the European context where funding targeted at social cohesion and education comes from the European Union, that many of the initiatives can only be sustained whilst the funding is available, after which a substantial part of this innovative work is terminated together with expiration of the funding. In the case studies reported contribution of both principals went beyond the initial funding. They were committed to the continuation of parental involvement and they made substantial sacrifice in order to provide school with the necessary resources.

Although the two principals did not act alone in leading the case study schools, it is important to note that findings indicate that the role of the principal is pivotal in ensuring schools' success in encouraging parental involvement. These principals did not simply respond to what was happening in the external and internal contexts. Rather, they seemed to have the ability to look to the future so that their vision for change was one that amply prepared the school to respond to future challenges or opportunities. In effect, they (re)positioned the school.

Findings show that, because principals' strategic vision in this area was both clearly communicated and responsive to the many different dimensions of school context, members of staff were more likely to put trust in them and participate positively in the direction of school change. Thus, although the strategic vision was the main driving force behind change within these schools, staff did not feel that this was imposed upon them, but that it was a vision that included them and that took the school in a positive direction which result in a collective sense of success. This was a visible result of distribution of leadership. Both principals invested their time in meetings and discussions with their staff at every stage of the 
implementation process. They were charismatic enough to inspire teachers and encourage them to create tailor-made solutions.

The role of the principal was crucial in fostering this culture of change, and was the key drivers in facilitating parental involvement in school activities. In particular, it seems that the ways they responded constructively to local or national policy initiatives helped to foster a climate where staff viewed participation in these changes more positively. In this way, changes in the school to involve parents were not seen as impositions, but as opportunities for the school to examine and improve its current practices. Teachers and principals familiarized with particular needs of parents from ethnic minority groups, especially those from a low socio-economic background, and low social background parents were able to respond to these needs constructively. They treated parents not only as partners engaged in the education of their children but also as community members and parents who should be provided with certain skills in order to empower them. This is one of the reasons of the success of this project. Often official policies neglect the actual skills of parents and, in turn, many of the initiatives result in a perceived increase in the existing gap between less and more affluent parents.

The school was successful regarding the sustainability of the projects. As the initiatives focused on pupils' achievements and parental involvement have been developed for five years the school proved to be successful in funding its activities through variety of the schemes. Funding schemes at the local and regional levels have been frequently modified posing a considerable challenge upon the administration. Nonetheless, continuity of the strong ties with the local community and improved parental involvement resulted in positive image of the school in the local setting. This research argues that parents have seen the benefits related to their involvement in school and, as the engagement of the principals and school staff has been developed, people volunteered to be involved in the school activities regardless of funding. Some of the initiatives, e.g. courses, run in school are heavily dependent on external funding and school cannot provide these services basing on volunteers only. Therefore, over the years the school leaders have worked out creative ways to use their budgets so that they can continue to fund activities until another funding opportunity comes along. They also have appointed person who works with both schools and who looks at funding opportunities for them. Yet, externally funded activities have been running for a few years which have made them more cost-effective.

\section{Limitations of the Study}

It is important to acknowledge the limitations of this study in order to appreciate fully the context within which it was conducted. A major limitation to any collaborative study in which a number of different educational environments are involved is the need for consistency across all settings. In this case, the school selection criteria, although applicable to the UK context, did not closely relate to the on-going work in schools related to parental engagement. In addition, UK schools are complex environments, and the restriction of 1-2 case study schools did not give enough flexibility to explore some of the emerging issues regarding the importance of strong, focused leadership on the increasing parental participation and 
engagement to their full extent.

\section{Conclusion}

This study aimed to examine ways in which strong leaders contribute to the social cohesion in a highly disadvantaged area through increased parental involvement. Findings demonstrated that initiatives facilitated and supported by the school principals were successful in improving this aspect of school-community relationships and also, indirectly, in improving pupils' academic achievements. The community of parents, volunteers and professionals involved in the schools is considered one of the most important results of the principals' actions.

Following the example of the Harvard Family Research Project (hereafter HFRP), a world's leading institution which promotes parental involvement in schools, the conclusions from this project should bring attention to three crucial points. Firstly, parental involvement in schools should be a high priority and be explicitly acknowledged on university initial teacher training provision. Future teachers should be instructed on the importance of this issue. Secondly, rather than a series of disconnected projects focused on parental involvement, this important factor of school life should be embedded in educational policy, advocating an integrated approach to family engagement in schools. .

Finally, initiatives like those reported here which are undertaken by school principals and focus on increased parental involvement, should begin by informally assessing the existing skills and knowledge possessed by the parents. Embracing parents in learning process of their children calls for innovative solutions but only holistic vision and strong leadership is able to meet the current challenges in schools.

\section{Acknowledgements}

The project 'Strategies for Inclusion and Social Cohesion in Europe through Education (Includ-Ed)' was funded by the European Commission as part of the EU 6th Framework Integrated Programme. We would like to acknowledge the contribution of the project consortium and give a special thanks to Professor John Holford and Dr. Thushari Welikala for their involvement in the project.

\section{References}

Adelman, H., \& Taylor, L. (2008). Fostering School, Family, and Community Involvement. Washington D.C.: George Washington University.

Auerbach, S. (2009). Walking the Walk: Portraits in Leadership for Family Engagement in Urban Schools. The School Community Journal, 19, 9-32.

Barth, R. (1990). Improving schools from within: Teachers, parents, and principals can make the difference. San Francisco, CA: Jossey-Bass.

Bouffard, S. M., \& Stephen, N. (2007). Promoting Family Involvement. Principal's Research Review, 2(6), 1-8. 
Bredson, P. W. (1985). An analysis of the metaphorical perspectives of school principals.

Educational Administrative Quarterly,

21 , 29-50. http://dx.doi.org/10.1177/0013161X85021001004

Burns, J. M. (1978). Leadership. New York: Harper \& Row.

Cespe, M., Lopez, E., Chu, A., \& Weiss, H. B. (2011). Teaching the Teachers: Preparing Educators to Engage Families for Student Achievement. Issue Brief, May 2011.

Ciuffatelli Parker, D. C., Grenville, H., \& Flessa, J. (2011). Case Studies of School Community and Climate: Success Narratives of Schools in Challenging Circumstances. The School Community Journal, 21(1), 129-150.

Davies, D. (1988). Low-income parents and the schools: A research report and a plan for action. Equity and choice, 4(3), 51-57.

Denessen, E., Bakker, J., \& Gierveld, M. (2007). Multi-Ethnic Schools' Parental Involvement Policies and Practices. The School Community Journal, 17(2), 27-44.

DiMaggio, P. J. (1988). Interest and agency in institutional theory. In L. G. Zucker (Ed.), Institutional Patterns and Organizations: Culture and Environment (pp. 3-21). Cambridge, MA: Ballinger.

Epstein, J. L., \& Salinas, K. C. (2004). Partnering with families and communities, Educational Leadership, 61(8), 12-18.

Fink, E., \& Resnick, L. (2001). Developing Principals as Instructional Leaders. Phi Delta Kappa, 82, 598-606.

Fullan, M. (2002). The Change Leader. Educational Leadership, 59(8), 16-21.

Griffith, J. (2001). Principal leadership of parent involvement. Journal of Educational Administration, 39(2), 162-186. http://dx.doi.org/10.1108/09578230110386287

Gronn, P. (2000). Distributed Properties. A New Architecture for Leadership. Educational Management \& Administration, $\quad$ 28(3), 317-338. http://dx.doi.org/10.1177/0263211X000283006

Hallinger, P., \& Hausman, C. (1993). From Attila the Hun to Mary had a little lamb: redefining principal roles in restructured schools. Paper presented at the Annual Meeting of the American Education Research Association, Atlanta, GA. 1993. ERIC ED 359647.

Harris, S. (2007). The best from the Best: Effective Strategies of Award-winning Principals. Principal. September/October. 2007 (accessed online 20 March 2012).

Harris, A., Andrew-Power, K., \& Goodall, J. (2009). Do Parents know they Matter? Raising achievement through parental engagement. London: Network Continuum Education.

Henderson, A. T., \& Mapp, K. L. (2002). A New Wave of Evidence: the Impact of Family, School, and Community Connections on Student Achievement. Austin, TX: Southwest Educational Development Laboratory. 
Ho, E. S. (2009). Educational Leadership for Parental Involvement in an Asian Context: Insights from Bourdieu's Theory of Practice. The School Community Journal, 19(2), 101-122.

Hoover-Dempsey, K., \& Sandler, H. (1997). Parental involvement in children's education: Why does it make a difference? Teachers College Record, 97, 310-332.

Kington, A., Holford, J., Engel, L., \& Restorick, J. (2010). Strategies for Inclusion and Social Cohesion in Europe from Education: Case studies of local projects. Report for the European Commission - Project 6 (4). Barcelona: CREA.

Mapp, K. (2003). Having Their Say: Parents Describe Why and How They Are Engaged in Their Children's Learning. The School Community Journal, 13(1), 35-65.

Martin, A. Linfoot, K., \& Stephenson, J. (1999). How teachers respond to concerns about misbehaviour in their classroom. Psychology in the Schools, 36, 347-358. http://dx.doi.org/10.1002/(SICI)1520-6807(199907)36:4<347::AID-PITS7>3.0.CO;2-G

Park, H. (2008). The Varied Educational Effects of Parent-Child Communication: A Comparative Study of Fourteen Countries. Comparative Education Review, 52(2), 19-245. http://dx.doi.org/10.1086/528763

Rosenberg, H., \& Lopez, M. E. (2011). New Learning Opportunities Mean New Opportunities for Engagement. Family Involvement Network of Educators (FINE) Newsletter. III (4).

Rosenberg, H. (2012). Creating Conditions for Effective and On-going Family Engagement. Family Involvement Network of Educators (FINE) Newsletter. IV (3).

Sanders, M. G., \& Harvey, A. (2002). Beyond the School Walls: A Case Study of Principal Leadership for School-Community Collaboration. Teachers College Record, 104(7), 1345-1368. http://dx.doi.org/10.1111/1467-9620.00206

Sheldon, S. B., \& Epstein, J. L. (2004). Getting students to school: Using family and community involvement to reduce chronic absenteeism. School and Community Journal, 4(2), $39-56$.

Sherer, J. Z. (2008). Power in distributed leadership: How teacher agency influences instructional leadership practice. Paper presented at the American Educational Research Association Meeting, New York, NY. 2008

Spillane, J. P. Halverson, R., \& Diamond, J. B. (2004). Towards a theory of leadership practice: a distributed perspective. Journal of Curriculum Studies, 36(1), 3-34. http://dx.doi.org/10.1080/0022027032000106726

Stake, R. E. (1995). The Art of Case Study Research. London: Sage.

Thurston, D. (2005). Leveling the Home Advantage: Assessing the Effectiveness of Parental Involvement in Elementary School. Sociology of Education, 78(3), 233-249. http://dx.doi.org/10.1177/003804070507800303 


\section{Macrothink}

Warren, M. R., Hong, S., Rubin, C. H., \& Uy, P. S. (2009). Beyond the Bake Sale: A Community-Based Relational Approach to Parent Engagement in Schools. Teachers College Record, 111(9), 2209-2254.

\section{Notes}

1. Pseudonyms are used in this article to protect anonymity of respondents and institutions.

2. The school's Contextual Value Added (CVA) is a statistical means of assessment of how effective a school is, by measuring pupils' progress using their test and examination results. The most recent Annual Performance Review report for the Junior School shows a CVA score of over 101, signifying that the school is in the top 5\% of all similar schools across England. Using CVA criteria, the most recent SATs results showed major gains in Level 4+ attainment across English, Mathematics and Science content areas.

3. Findings from the questionnaire survey data are reported in Kington, Holford, Engel and Restorick (2010).

4. For more information on Creative Partnerships in England, see http://www.creative-partnerships.com/

\section{Copyright Disclaimer}

Copyright reserved by the author(s).

This article is an open-access article distributed under the terms and conditions of the Creative Commons Attribution license (http://creativecommons.org/licenses/by/3.0/). 